\title{
Advanced Logistics Planning for Offshore Wind Farm Operation and Maintenance Activities
}

\author{
Yalcin Dalgic $^{1}$, Iraklis Lazakis ${ }^{1}$, Iain Dinwoodie ${ }^{2}$, David McMillan², Matthew Revie ${ }^{3}$ \\ ${ }^{1}$ Department of Naval Architecture, Ocean and Marine Engineering, University of Strathclyde, Glasgow, UK \\ ${ }^{2}$ Institute for Energy \& Environment, University of Strathclyde, Glasgow, UK \\ ${ }^{3}$ Department of Management Science, University of Strathclyde, Glasgow, UK
}

\begin{abstract}
Offshore wind turbine technology is moving forward as a cleaner alternative to the fossil fuelled power production. However, there are a number of challenges in offshore; wind turbines are subject to different loads that are not often experienced onshore and more importantly challenging wind and wave conditions limit the operability of the vessels needed to access offshore wind farms. As the power generation capacity improves constantly, advanced planning of Operation and Maintenance (O\&M) activities, which supports the developers in achieving reduced downtime, optimised availability and maximised revenue, has gained vital importance. In this context, the focus of this research is the investigation of the most cost-effective approach to allocate O\&M resources which may include helicopter, crew transfer vessels, offshore access vessels, and jack-up vessels. This target is achieved through the implementation of a time domain Monte-Carlo simulation approach which includes analysis of environmental conditions (wind speed, wave height, and wave period), operational analysis of transportation systems, investigation of failures (type and frequency), and simulation of repairs. The developed methodology highlights how the O\&M fleets can be operated in a cost-effective manner in order to support associated day-to-day O\&M activities and sustain continuous power production.
\end{abstract}

Keywords: Offshore Wind, Operation and Maintenance, Accessibility, Charter Rate, Simulation, Logistics Planning

\section{Introduction}

Wind power industry has continued to grow rapidly in recent years with major developments in offshore wind farms. The availability of large areas in order to locate major projects, the lack of existing limitations associated with visual impact and noise, higher wind speeds, and the lower turbulence levels in the offshore environment have encouraged operators to invest in offshore wind farms. Despite all these advantages, power production from offshore wind is still significantly more expensive than power generation from onshore wind farms. This is due to more complicated foundations, longer electrical networks, installation and maintenance activities that are dependent on vessels, and harsher climate conditions that limit the operability of vessels and subsequently the accessibility of offshore wind farms. Considering the UK with the greatest operating capacity in its waters, offshore wind Levelised Cost of Energy (LCOE) reached £140/MWh in 2011 (The Crown Estate, 2012); whilst onshore wind LCOE is £74/MWh (WindPower Offshore, 2012).

Corresponding Author: Yalcin Dalgic 12

Tel: +44 (0)141548 4778, +44 (0)141548 4094

Fax: +44 (0)141 5522879

E-mail Address: yalcin.dalgic@ @strath.ac.uk

Postal Address: Department of Naval Architecture, Ocean and Marine Engineering, University of Strathclyde, 100 Montrose 
Operation and Maintenance (O\&M) is a significant contributor to the LCOE. The Renewables Advisory Board (2010) reported that offshore access related operations including the cost of maintenance dominate the total offshore wind ongoing costs by $84 \%$, whilst other costs such as licence fees, administration, and insurance account for $16 \%$. Current O\&M activities in the offshore wind market is valued around $£ 400 \mathrm{~m} / \mathrm{year}$ and expected to increase to $£ 950 \mathrm{M} /$ year by 2020 ; simultaneously, around $40 \%$ of the offshore wind turbines in the UK are now approaching the end of warranty periods (WindPower Offshore, 2014). During the warranty period, Original Equipment Manufacturers (OEMs) are responsible for all the O\&M activities. In the post-warranty period, the responsibility of minimising O\&M costs and optimising operations may shift to the owners and the operators.

The focus of this paper is to design and develop a discrete-event simulation model of an offshore wind farm that allows the identification of favourable operating strategies for offshore wind O\&M fleets. The aim is to provide decision support to operators trying to manage a portfolio of wind turbines and a fleet of vessels for the midterm ( $\sim 5$ years) offshore wind O\&M planning. The model builds upon the existing literature by considering different climate parameters, failure characteristics of the turbine components and the operational characteristic of the transportation systems. The combination of the various O\&M strategies defines a particular scenario, and the simulation model developed allows the operator to assess the different strategies and compare them in terms of generated revenue.

The remainder of the paper is structured as follows. Section 2 reviews common procedures, aspects and issues associated with maintenance of offshore wind farms, and existing offshore wind O\&M models. The modelling methodology is explained in Section 3. A case study is presented in Section 4 in order to illustrate the developed approach. In Section 5, the results of the case study are evaluated. Subsequently, final recommendations are provided in Section 6. 


\section{Literature Review}

\subsection{Economic aspects}

O\&M activities represent a significant share of the ongoing expenses during the lifecycle of the offshore wind projects (Kaldellis and Kapsali, 2013). The O\&M costs comprise of labour costs (technician costs), material costs (component cost), transportation costs (vessels and associated cost), fixed costs (port, insurance, bidding, etc.) and potential revenue losses. In this respect, it is important to identify the critical aspects that can significantly reduce overall costs. It has been identified that the costs associated with transportation systems account for 73\% of the total O\&M costs (Dinwoodie et al., 2013; Fingersh et al., 2006; Junginger et al., 2004; Krohn et al., 2009). In addition, Van Bussel and Zaaijer (2001) demonstrated that the cost of lifting operations using a vessel accounts for more than $50 \%$ of the overall O\&M costs. Therefore, O\&M activities have to be planned carefully, considering the fact that economic benefits from producing more energy by increasing the availability does not always lead to higher profits, since the increase in the total O\&M costs may not be compensated (Dalgic et al., 2015b; Santos et al., 2013).

\subsection{Transportation systems}

The main tasks of the transportation systems in a maintenance operation are to provide accommodation for crew and technical personnel, loading, transporting and assembling failed turbine components in the offshore environment. During the operational span of an offshore wind farm, a number of scheduled and unscheduled maintenance tasks have to be performed in order to keep the turbines operational and to sustain power generation. In this respect, there are two main categories of O\&M vessels in the offshore wind energy market: vessels for minor maintenance and vessels for major maintenance.

Regarding vessels for minor maintenance, current transportation methods to offshore wind turbines include mostly the use of small workboats which involves long shuttling journey times resulting in considerable wasted technician time (Dalgic et al., 2015a; Dalgic et al., 2015c). Monohull boats, small catamaran vessels and Small Waterplane Area Twin Hull (SWATH) vessels are generally utilised in minor maintenance operations, which allow operators to keep the costs at acceptable levels. Catamaran configurations are often the preferred choice but operations are restricted to relatively low wave heights (Tavner, 2012). Access and O\&M of offshore wind turbines are severely impacted by very poor weather tolerance, particularly in further offshore locations (Walker et al., 2013). In some cases, operators consider a helicopter in the O\&M fleet in order to provide access when 

the crew transfer vessels (CTVs) are not able to sail due to rough met-ocean conditions. Both transportation systems (CTV and helicopter) involve significant amount of costly and inefficient travel for technicians; in addition relatively small vessels pose a significant risk of capsizing in rough weather conditions (Al-Salem et al., 2006). In addition to conventional CTVs, Offshore Access Vessels (OAVs) are occasionally considered by the offshore wind operators in their O\&M fleets. These larger vessels $(\sim 50 \mathrm{~m})$ have better operational capability than conventional CTVs and are generally equipped with dynamic positioning systems. Additionally, motioncompensating gangways are typically installed on OAVs in order to transfer technicians on the wind turbine in rough weather, in which CTVs cannot operate (Dai et al., 2013; O'Connor et al., 2013). Cranes on these vessels provide ability to transfer medium weight components from vessels' deck directly to offshore wind turbine platforms. OAVs are designed to stay in the offshore wind farms longer periods and therefore the travels between the sites and the O\&M ports are minimised. These advantages make OAVs an adequate candidate for the offshore wind O\&M activities. However, the charter cost of these vessels are higher than CTVs, which is a major issue considering the fact that the operators intend to minimise the O\&M costs. The generic criteria related to human performance are well established for seamen but not so well established for O\&M technicians (Wu, 2014). In addition, quality and duration of sleep are impaired by disturbance associated with ongoing tasks and environmental factors (e.g. noise, shared cabins, poor air quality) in offshore environment; and therefore has adverse effects on day-to-day performance and alertness of the O\&M technicians (Anderson and Horne, 2006; Belenky et al., 2003; Parkes, 2010; Townsend et al., 2012). Moreover, the use of OAVs is not well defined due to immaturity of the industry. Therefore, OAVs are not considered as a permanent solution like CTVs; instead, these vessels are chartered for shorter periods.

In the case of blade, generator, gearbox or tower failures, small maintenance vessels are not adequate to perform the replacement of damaged components. Instead, one of the jack-up, leg-stabilised or heavy lift vessels has to be utilised considering the properties of damaged component (height, weight, etc.) and the capability of the vessel (lifting capacity, operational water depth, etc.). Jack-up vessels are capable of raising their hulls over the sea-surface, station their legs on the sea floor, which provides very stable environment for crane operations under rough sea conditions. Leg-stabilised vessels are very similar to the jack-up vessels. Instead of lifting the 
hull over the sea surface, leg-stabilised vessels, which are ideal for operations in shallow sites, use their legs to stabilise the hull. However, the number of leg stabilised vessels is considerably low in the market (EWEA, 2011). Heavy lifters are capable of lifting extensive loads, which can be experienced in offshore wind industry; on the other hand the charter rates of heavy lifting vessels are excessively high (Dalgic et al., 2014; DNV, 2011). Therefore, jack-up vessels are the most utilised vessels for major maintenance operations in offshore wind energy market (Dalgic et al., 2015d).

\subsection{Existing offshore wind O\&M models}

To support operators in optimising O\&M activity, different models have been developed to analyse offshore wind O\&M activities. CONTOFAX, developed by TU Delft, utilises Monte-Carlo simulations to analyse state of every component over a period of time (Bussel and Schöntag, 1997). Bussel and Bierbooms (2003) investigated inflatable boats, special offshore transportation systems and helicopters for offshore wind farm O\&M activities. The BMT group developed the BMT MWCOST model that considers the significant wave height observations as a limitation for the vessel access (Stratford, 2007), while GL-Garrad Hassan's O2M model, based on work conducted by Bossanyi and Strowbridge (1992), takes the wave height values into account and performs time domain Monte-Carlo simulations (Philips et al., 2006). Other models have investigated integration of remote condition monitoring and fault prediction hardware and software into O\&M strategies (Lyrner et al., 2006) or considering corrective maintenance activities and wind forecasting (Besnard et al., 2009). The ECN O\&M Tool is generally considered to be the most comprehensive tool for analysing O\&M costs and downtime (Curvers and Rademakers, 2004a, b; Ramakers et al., 2004) and has received a validation statement from Germanischer Lloyd (Rademakers et al., 2011).

There are limitations with the current portfolio of developed models. None of the previously mentioned models consider additional climate parameters such as wave period or visibility within their climate modelling. In addition, these models are not able to demonstrate the influence of different operating strategies for the entire O\&M fleet. Subsequently, offshore access related operations are generally overly simplified or modelled in a crude way. Different transportation systems such as CTVs, helicopters, and jack-up vessel are highly utilised within an offshore project lifecycle, the influence of these transportation systems on the O\&M lifecycle cost cannot be thoroughly considered from the previously mentioned models. Given the contribution of O\&M to 
LCOE, a better understanding about the usage of different transportation systems is required. From this, a favourable operating strategy for the entire O\&M fleet can be developed.

\section{Methodology}

In this study, a time domain Monte-Carlo simulation approach is implemented in order to identify possible improvements for the planning of offshore wind O\&M activities. In this respect, the major aspects that influence the O\&M activities are modelled in a comprehensive manner. In addition, an advanced O\&M fleet model is developed to support the offshore wind farm operators/developers in the decision stage. In this context, Figure 1 shows the flowchart of the developed methodology illustrating the information flow between different sections. The developed methodology is divided into three main sections: Inputs, Simulations, and Outputs. The inputs section is the stage that the information about a case is defined and this specific information is delivered to simulations section. Thereafter, the specific information is processed, analysed within specific sub-sections and the operational simulations are performed. The results of the operational simulations are averaged in the outputs section and final results are presented. In the following sections details are provided related to each section and sub-section of the proposed approach.

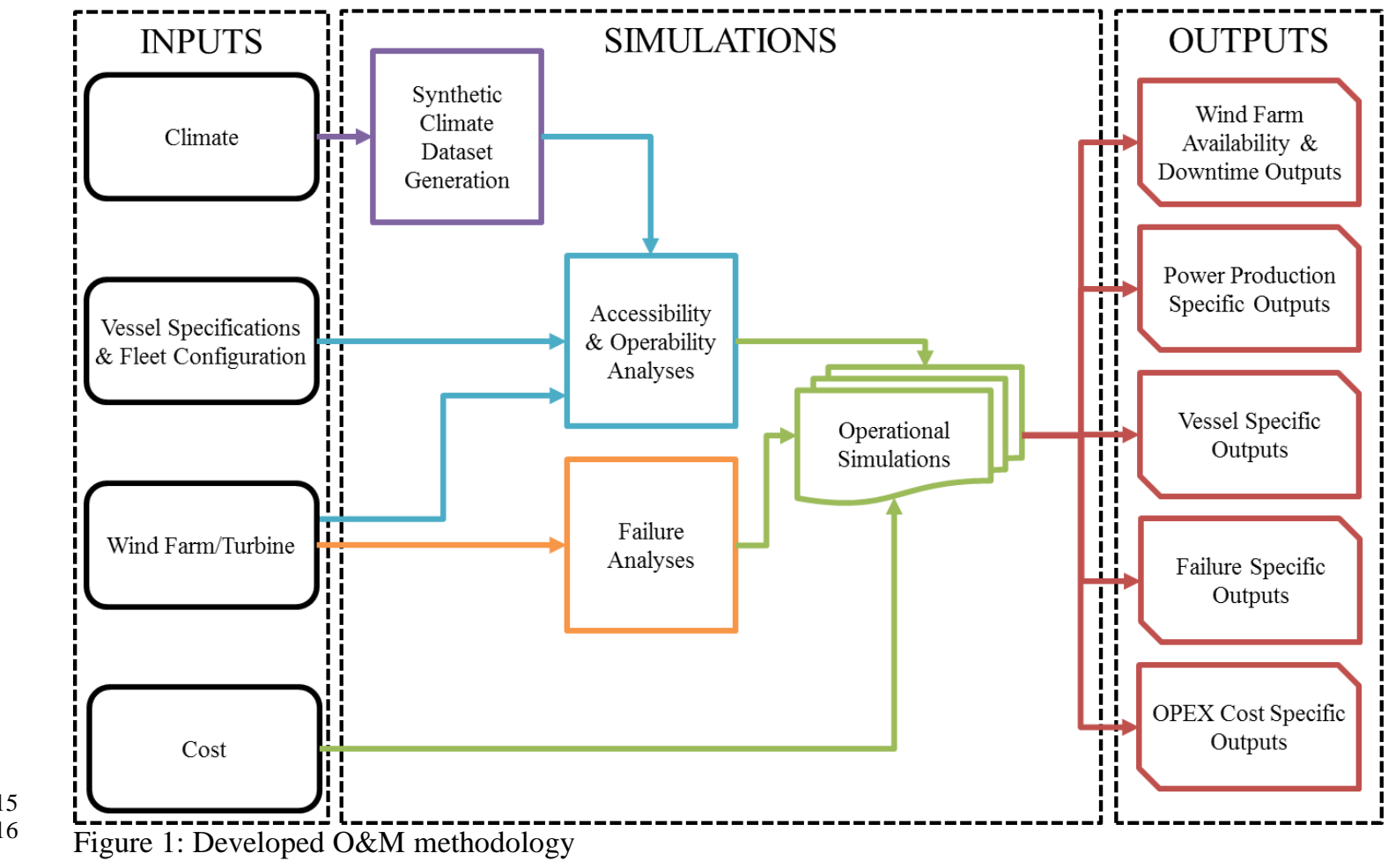




\subsection{Simulation inputs}

The simulation inputs introduce the information that has to be defined to run the O\&M simulations. In order to improve the reading quality of the article, the name and the explanation of the inputs are provided in the tables at the end of each section. In this context, the numbers within the brackets "[ ]" denote the inputs. Selfexplanatory inputs are referred and only described in the associated tables.

\subsubsection{Climate}

Climate inputs [1-7] in the developed methodology are explained in Table 1. Offshore access by vessels/helicopter is influenced by the inputs [1-5]; whilst the turbine power production is only influenced by the input [1]. The inputs [4-5] are utilised to calculate the length of period with sun light in each working shift, which is a constraint for CTV, helicopter, and OAV access. The input [6] is related to the helicopter operations, since helicopters can only fly if the visibility is sufficient enough (Joint Aviation Authorities, 2004). If the wind speed observations are measured from a single altitude, these values have to be extrapolated/interpolated to the hub level and sea level. In this context, sea level observations are used for the operational activities; on the other hand, hub level observations are used for the power production calculations, for the maintenance activities that require equipment lifting, and also for the helicopter access. Although there are many models to extrapolate wind speed to different altitudes, the wind power law developed by Justus and Mikhail (1976) is the most widely used method (Firtın et al., 2011); therefore, the wind power law in Equation 1 is adopted to calculate the wind speed values at hub level and sea level.

$$
v_{2} / v_{1}=\left(h_{2} / h_{1}\right)^{\alpha}
$$

\section{Equation 1}

where $v_{2}$ is wind speed at height $h_{2}, v_{1}$ is wind speed at height $h_{1}$. The input [7] $\alpha$ is not a constant value; it varies depending on atmospheric conditions, temperature, pressure, humidity, time of the day and nature of terrain (Manwell et al., 2009).

Table 1: Climate inputs

\begin{tabular}{llll}
\hline No & Name & Explanation & Unit \\
\hline 1 & Wind speed & Historical wind speed observations & $\mathrm{m} / \mathrm{s}$ \\
2 & Wave height & Historical wave height observations & $\mathrm{m}$ \\
3 & Wave period & Historical wave period observations & $\mathrm{sec}$ \\
4 & Sun-rise time & Sun-rise times in each day of the year & $\mathrm{hh}: \mathrm{mm}$ \\
5 & Sun-set time & Sun-set times in each day of the year & $\mathrm{hh:mm}$ \\
6 & Probability of good visibility & Probability of good visibility for each month of the year & $\%$ \\
7 & Shear component & Constant for wind power law equation & $\mathrm{N} / \mathrm{A}$ \\
\hline
\end{tabular}


In addition to the explanation of the climate inputs, the limiting climate aspects for each transportation system are provided in Table 2. It is assumed that the CTVs and helicopter can perform technician transfer after the sun rises; in the same manner the CTVs and helicopter have to sail/fly back to the maintenance port before the sun sets. In the context of visibility, a random number between 0 and 100 is generated (in order to be consistent with the probability of good visibility values) for each day of the simulations. If the randomly generated number in a particular repair day is higher than the probability of good visibility value associated with that particular month, the helicopter operations are ceased for that repair day. On the contrary, if the randomly generated number is lower than the probability of good visibility value of that month, the helicopter can be utilised.

Table 2: Weather constraints for transportation systems

\begin{tabular}{|c|c|c|c|c|c|}
\hline No & Name & CTV & Helicopter & OAV & Jack-up Vessel \\
\hline 1 & Wind speed at sea level & $\sqrt{ }$ & $\checkmark$ & $\sqrt{ }$ & $\sqrt{ }$ \\
\hline 2 & Wind speed at hub level & & $\checkmark$ & & $\checkmark$ \\
\hline 3 & Wave height & $\checkmark$ & $\checkmark$ & $\checkmark$ & $\checkmark$ \\
\hline 4 & Wave period & $\checkmark$ & & & \\
\hline 5 & Sun-rise time & $\checkmark$ & $\checkmark$ & $\checkmark$ & \\
\hline 6 & Sun-set time & $\checkmark$ & $\checkmark$ & $\checkmark$ & \\
\hline 7 & Probability of good visibility & & $\checkmark$ & & \\
\hline
\end{tabular}

\subsubsection{Vessel specifications \& fleet configuration}

The vessel specifications and fleet configuration sub-section comprises of CTV, helicopter, OAV, and jack-up vessel specific inputs. The CTV inputs [1-12] display the generic characteristics of the CTVs (Table 3). The input [13] is the time that day shift starts, for which the length of a day shift is assumed to be 12 hours in the developed methodology. Due to safety constraints, the offshore wind operators may need to define the input [14] in order to limit the maximum number of operations that can be done by a CTV in a single shift; so that the CTVs can react to emergency situations quicker. The inputs [15-17] are the additional parameters required to present the operational practice in a more advanced manner. 
Table 3: Transportation inputs (CTVs)

\begin{tabular}{llll}
\hline No & Name & Explanation & Unit \\
\hline 1 & Number of CTVs & Size of CTV fleets & vessel \\
2 & Vessel type & Hull type of CTV & $N / A$ \\
& & $\begin{array}{c}\text { - Catamaran } \\
\text { Monohull }\end{array}$ & m \\
3 & Length & Vessel length & m \\
4 & Breadth & Vessel breadth & m \\
5 & Draught & Vessel displacement & ton \\
6 & Displacement & Total installed power & kW \\
7 & Installed power & Total technician capacity & person \\
8 & Technician capacity & Speed at maximum continuous power & knot \\
9 & Operational speed & Fuel consumption at operational speed & mt/hour \\
10 & Fuel consumption & Limiting wave height & m \\
11 & Max. op. wave height & Limiting wind speed at sea level & m/s \\
12 & Max. op. wind speed & The start time of the shift & hh: mm \\
13 & Shift start & Maximum number of operations that can be done by a CTV in a single shift & turbine \\
14 & Maximum visit per CTV & minute \\
15 & Inter transit time & Time required to travel between turbines & minute \\
16 & Time to start work & Time required to transfer equipment from CTV to nacelle level & hour \\
17 & Minimum working limit & Minimum productive time for making a working shift cost-effective &
\end{tabular}

Although helicopters are not widely utilised at present in the offshore wind farm O\&M activities, they have different operational characteristics than other marine transportation systems; therefore, helicopter operations are also considered in the methodology in addition to conventional transportation systems. The helicopter specific inputs [1-5] are listed in Table 4. Due to high capital investment required, offshore wind farm operators generally charter a helicopter for a certain number of annual flying hours as the input [1]. The inputs [2-5] display the generic characteristics of the helicopter. It is assumed that helicopter and CTV working shifts start at the same time.

Table 4: Transportation inputs (Helicopter)

\begin{tabular}{llll}
\hline No & Name & Explanation & Unit \\
\hline 1 & Contract hour & Certain number of annual flying hours & hour \\
2 & Operational speed & Speed at maximum continuous power & knot \\
3 & Fuel consumption & Fuel consumption at operational speed & $\mathrm{mt} /$ hour \\
4 & Max. op. wave height & Limiting wave height & $\mathrm{m}$ \\
5 & Max. op. wind speed & Limiting wind speed at hub level & $\mathrm{m} / \mathrm{s}$ \\
\hline
\end{tabular}

The OAV specific inputs [1-6] are listed in Table 5. The OAV is envisaged to have a motion compensating system for the technician transfer and a crane to transfer the mid-size components from OAV's deck to turbine's lower platform. Due to high capital investment requirement, it is assumed that the offshore wind farm operators charter an OAV for the period defined as the input [1]. A mobilisation fee is often included for specialised 

vessels to compensate the vessel owner for the time and expense to get the vessel on site and ready for work. The vessel owner then charges by the day as the vessel is operated. Likewise, the input [2] has to be defined in order to address the period between the vessel is chartered and it arrives at the offshore wind farm location. The inputs [3-6] display the generic characteristics of the OAV. It is assumed that OAV and CTV working shifts start at the same time.

Table 5: Transportation inputs (OAV)

\begin{tabular}{llll}
\hline No & Name & Explanation & Unit \\
\hline 1 & Charter length & Certain number of charter days & day \\
2 & Mobilisation time & Time required for vessel arrival & day \\
3 & Operational speed & Speed at maximum continuous power & $\mathrm{knot}$ \\
4 & Fuel consumption & Fuel consumption at operational speed & $\mathrm{mt} / \mathrm{hour}$ \\
5 & Max. op. wave height & Limiting wave height & $\mathrm{m}$ \\
6 & Max. op. wind speed & Limiting wind speed at sea level & $\mathrm{m} / \mathrm{s}$ \\
\hline
\end{tabular}

In the case of wind turbine blade, generator, gearbox or tower failures, CTVs or OAVs cannot perform the replacement of damaged components; therefore, a jack-up vessel is chartered or purchased. In the maritime industry, voyage charter, time charter and bareboat charter are the commonly used types of contractual arrangements (Stopford, 2009; Watson, 1998). The jack-up vessel chartering strategy is adopted from Dalgic et al. (2014).

In this context, the jack-up vessel specific inputs [1-15] are listed in Table 6 . If the vessel is purchased, the inputs [2-6] are not taken into account. For the fix of fail alternative, there is a significant uncertainty on the mobilisation time due to the insufficient number of jack-up vessels in the offshore wind market. Therefore, the mobilisation time for the jack-up vessel operations is defined through the selection of a random value from a triangular distribution, for which the lower limit, mode and upper limit are indicated by the inputs [3-5], respectively. 
Table 6: Transportation inputs (Jack-up vessel)

\begin{tabular}{|c|c|c|c|}
\hline No & Name & Explanation & Unit \\
\hline 1 & Charter type & $\begin{array}{l}\text { Type of the contractual agreement } \\
\text { - Fix on fail } \\
\text { - Purchase }\end{array}$ & $N / A$ \\
\hline 2 & Charter length & Certain number of charter days & day \\
\hline 3 & Mobilisation time (opt.) & Mobilisation time in optimistic scenario & day \\
\hline 4 & Mobilisation time (exp.) & Mobilisation time in expected scenario & day \\
\hline 5 & Mobilisation time (pes.) & Mobilisation time in pessimistic scenario & day \\
\hline 6 & Batch repair threshold & Number of subsequent failures before chartering a jack-up vessel & failure \\
\hline 7 & Component capacity & Number of components that jack-up vessel can transport & component \\
\hline 8 & Port re-supply time & Time required to replenish provisions, fuel, water, etc. & hour \\
\hline 9 & Jack-up time & Time required for jacking up & hour \\
\hline 10 & Hub removal time & Time required for removing hub & hour \\
\hline 1 & Operational speed & Speed at maximum continuous power & knot \\
\hline 12 & Fuel consumption & Fuel consumption at operational speed & mt/hour \\
\hline 13 & Max. op. wave height & Limiting wave height & $m$ \\
\hline 14 & Max. op. wind speed & Limiting wind speed at sea level & $\mathrm{m} / \mathrm{s}$ \\
\hline 15 & Lifting wind speed limit & Limiting wind speed at hub level & $\mathrm{m} / \mathrm{s}$ \\
\hline
\end{tabular}

In some circumstances, if the power production is limited or the charter rates are significantly high, it might be cost-effective to wait (the input [6]) before chartering the jack-up vessel; so when the jack-up vessel arrives at the offshore wind farm, multiple failures can be repaired. It is assumed that the technicians on the jack-up vessel work 24 hours on three shift basis; therefore, a shift start input is not defined for the jack-up vessel operations. The inputs [7-15] display the generic characteristics of the jack-up vessel.

\subsubsection{Wind farm/turbine}

Table 7 shows the wind farm specific inputs [1-18]. The inputs [1-7] display the generic characteristics of the wind farm/turbines. The inputs [8-14] symbolise the failure specific aspects. The inputs [15-18] are related to the preventive maintenance activities. Through the definition of the input [18], the influence of different preventive maintenance practices can be investigated. In this context, 'Corrective maintenance or preventive maintenance', and 'Preventive maintenance after corrective maintenance', and 'Preventive maintenance only after corrective maintenance' are considered in the developed methodology. The O\&M technicians cannot perform preventive maintenance after corrective maintenance and therefore the teams have to be allocated to either corrective or preventive maintenance tasks, if 'Corrective maintenance or preventive maintenance' option is considered in the simulations. If 'Preventive maintenance after corrective maintenance' option is considered, 
is completed, so the teams cannot be allocated for only performing preventive maintenance. These three alternatives provide a detailed understanding about what order the preventive maintenance needs to be performed for increased power production.

Table 7: Wind farm/turbine inputs

\begin{tabular}{|c|c|c|c|}
\hline No & Name & Explanation & Unit \\
\hline 1 & Number of turbines & Number of turbines in the offshore wind farm & turbine \\
\hline 2 & Generation capacity & Generation capacity of each individual turbine in the wind farm & $M W$ \\
\hline 3 & Distance & Distance between the offshore wind farm and the maintenance port & nmile \\
\hline 4 & Hub height & The altitude of hub from sea level & $m$ \\
\hline 5 & Power curve & Power production value associated with different wind speed values & $N / A$ \\
\hline 6 & Cut in speed & Wind speed limit which the turbine starts to produce power & $m / s$ \\
\hline 7 & Cut out speed & Wind speed limit which the turbine stops to produce power & $m / s$ \\
\hline 8 & Failure mode & Failure name of failure type & $N / A$ \\
\hline 9 & Required repair time & Calendar hours to complete specified failure modes & hour \\
\hline 10 & $\begin{array}{l}\text { Required number of } \\
\text { technicians }\end{array}$ & $\begin{array}{l}\text { Number of technicians required to perform the repair of the specified failure } \\
\text { modes }\end{array}$ & person \\
\hline 11 & Transportation type & $\begin{array}{l}\text { Type of transportation which will be allocated when the associated failure modes } \\
\text { occur }\end{array}$ & $\mathrm{s} N / A$ \\
\hline 12 & Repair window & $\begin{array}{l}\text { Either cumulative window or single window to perform the repair of } \\
\text { specified failure modes }\end{array}$ & hour \\
\hline 13 & Failure impact & $\begin{array}{l}\text { The percentage of power production decrease when the associated failure } \\
\text { modes occur }\end{array}$ & $\%$ \\
\hline 14 & Failure distribution & Failure distribution of the specified failure modes & $N / A$ \\
\hline 15 & $\begin{array}{l}\text { Required preventive } \\
\text { maintenance }\end{array}$ & $\begin{array}{l}\text { Calendar hours to complete the preventive maintenance for } \\
\text { each turbine }\end{array}$ & hour \\
\hline 16 & $\begin{array}{l}\text { Preventive maintenance } \\
\text { technicians }\end{array}$ & Number of technicians required to perform the preventive maintenance & person \\
\hline 17 & $\begin{array}{l}\text { Preventive maintenance } \\
\text { start month }\end{array}$ & Start month of the preventive maintenance & $N / A$ \\
\hline 18 & $\begin{array}{l}\text { O\&M technician } \\
\text { allocation order }\end{array}$ & $\begin{array}{l}\text { The order of O\&M technician allocation } \\
\text { - Corrective maintenance or preventive maintenance } \\
\text { - Preventive maintenance after corrective maintenance } \\
\text { - Preventive maintenance only after corrective maintenance }\end{array}$ & $N / A$ \\
\hline
\end{tabular}

\subsubsection{Cost}

Table 8 shows the cost inputs [1-21]. The input [1] is required to calculate the total revenue, whilst the inputs [2-21] are associated with actual cost calculations. It is assumed that CTVs and helicopter are available at all times, effectively chartered for the life duration of the wind farm lifecycle; therefore, the inputs [2-6] are considered for the entire simulation period. The inputs [7-9] are only consider for the periods that the OAV is under charter agreement. If the jack-up vessel is charted for a certain period, the inputs [10-11] are taken into account; if the jack-up vessel is purchased, the inputs [12-13] are considered for the jack-up vessel associated costs. The inputs [14-17] are associated with the utilisation of the associated transportation systems. The inputs [18-21] are additional cost inputs, by which comprehensive examination on the cost drivers can be performed. 


\begin{tabular}{|c|c|c|c|}
\hline No & Name & Explanation & Unit \\
\hline 1 & Electricity price & Unit electricity price & $£ / M W h$ \\
\hline 2 & CTV charter cost & Charter cost of the CTV & $£ / d a y$ \\
\hline 3 & CTV technician cost & Cost of the CTV technician & $£ /$ year \\
\hline 4 & CTV fixed cost & Fixed cost of the CTV such as insurance, maintenance, etc. & $£ /$ year \\
\hline 5 & Helicopter charter cost & Charter cost of the helicopter & £/hour \\
\hline 6 & Helicopter technician cost & Cost of the helicopter technician (may require training) & $£ /$ year \\
\hline 7 & OAV charter cost & Charter cost of the OAV & $£ / d a y$ \\
\hline 8 & OAV mobilisation cost & Mobilisation cost of the OAV & $€$ \\
\hline 9 & OAV technician cost & Cost of the OAV technician & $£ /$ year \\
\hline 10 & Jack-up vessel charter cost & Charter cost of the jack-up vessel & $£ /$ day \\
\hline 11 & Jack-up vessel mobilisation cost & Mobilisation cost of the jack-up vessel & $£$ \\
\hline 12 & Jack-up vessel technician cost & Cost of the jack-up vessel technician (high skilled) & $£ /$ year \\
\hline 13 & Jack-up vessel CAPEX & Initial investment required to purchase the jack-up vessel & $€$ \\
\hline 14 & CTV fuel cost & Fuel cost of the CTV & $£ / m^{3}$ \\
\hline 15 & Helicopter fuel cost & Fuel cost of the helicopter & $£ / m^{3}$ \\
\hline 16 & OAV fuel cost & Fuel cost of the OAV & $£ / m^{3}$ \\
\hline 17 & Jack-up vessel fuel cost & Fuel cost of the jack-up vessel & $£ / m^{3}$ \\
\hline 18 & Preventive maintenance cost & Cost of materials and equipment required to perform the task & $£ /$ turbine/year \\
\hline 19 & Component repair cost & Cost of each component repair (only OEM) & £/repair \\
\hline 20 & Port and operations cost & Cost of port, repair dock, maintenance base, helipad, etc. & $£ /$ year \\
\hline 21 & Insurance cost & Insurance of the wind farm & E/year \\
\hline
\end{tabular}

\subsection{Simulations}

\subsubsection{Synthetic climate dataset generation}

5 Generally historical climate datasets are not sufficient to cover the entire lifecycle of offshore wind farms. Although the data may cover the past 20-25 years, it is rare that the climate data will present exactly the same track in the following years. On the other hand, it is important to generate datasets that preserve characteristics of the original dataset. The generation of different climate datasets minimises the uncertainty of the simulation results. If a single dataset is employed in the simulations, the risk of experiencing rougher climate conditions may be ignored. Similarly, experiencing lower wind speed values in the future may create risk on the power production values. Therefore, wind speed, wave height, and wave period historical time series are modelled; and the developed climate model is employed to generate wind speed, wave height, and wave period time series data at the beginning of each simulation. In this context, the modelling approach adopted in this work is a correlated Multivariate Auto-Regressive (MAR) approach. The general form for an AR model, normalised by the mean of the data is described in Equation 2.

$$
X_{t}=\mu+\varepsilon_{n}+\sum_{i=1}^{p} A_{n p}\left(X_{n-i}-\mu\right)
$$


where $X$ is the time series variable to be modelled with mean $\mu, p$ is the model order, $A$ is the correlation coefficient, $n$ is the simulated index and $\varepsilon$ is a random noise term.

Due to the presence of a Gaussian noise term $\varepsilon$, this equation is valid only for the datasets that can be approximated by a normal distribution. However, wind speed, wave height, and wave period datasets cannot be represented by a normal distribution and therefore the non-stationary trends have to be removed. By removing a fit of monthly mean and diurnal variation from wind speed dataset, the overall distribution approximates a normal distribution (Hill et al., 2012). For significant wave height, it is necessary to remove a fit of monthly mean values and then apply a logarithmic transformation on the data as shown in Equation 3 (Cunha and Guedes Soares, 1999). For wave period, it is only necessary to remove seasonal trends. For the multivariate case presented in this work, a modified Box-Cox transformation has been used in place of a logarithmic transformation, shown in Equation 4. The value of the transform coefficient $\Lambda$, can be tuned iteratively to capture the observed level of correlation between the wind and wave values in the data while preserving individual wave climate characteristics.

$Y_{t}=\frac{H s_{t}{ }^{\Lambda-1}}{\Lambda}$, for $\Lambda \neq 0$

Equation 3

$Y_{t}=T\left(H s_{t}\right)=\ln \left(H s_{t}\right)$, for $\Lambda=1$

Equation 4

The three de-trended series are then simulated. Correlation is captured by substituting the Gaussian pseudorandom vector normally used for $\varepsilon$ in Equation 4 with the covariance matrix of the three de-trended series. The determination of AR coefficients and model generation is implemented using the ARfit algorithm in MATLAB developed by Neumaier and Schneider (2001). Order is chosen by optimising Schwarz's Bayesian Criterion and coefficients using stepwise least squares estimation process. The simulation methodology maintains persistence characteristics, seasonality and correlation between wind speed, wave height, and wave period time series of the observed site.

\subsubsection{Accessibility \& operability analysis}

\subsubsection{CTV}

In order to represent the operational environment, the CTV operations are modelled in a comprehensive way representing a more sophisticated analysis approach than previous work in this area. In this context, transit time calculations are performed in each repair day, and 'Travel time', 'Non-productive time', and 'Productive time' 
values for each CTV in the O\&M fleet are calculated considering the fact that each time step has different climate conditions. The steps below are followed in the transit time modelling, and repeated for each CTV;

- Calculation of total efficiency

- Calculation of calm water resistance

- Calculation of added resistance and total resistance

- Calculation of speed loss and achievable speed for each time speed in waves

- Calculation of transit time and total fuel consumption through utilising achievable speed, time step interval and the total distance between local port and offshore wind farm

In the transit time calculations, the power and thrust are assumed constant; therefore, the fuel consumption of the vessel on the resolution basis will also be constant. However, due to the change in the vessel speed, there will be variations in the total time spent for the incoming and outgoing journeys that will create fluctuations in the fuel cost calculations. After calculating the achievable speed for each time step, the following step is the calculation of distance, which each CTV can log in each resolution interval.

Distance $_{i}=$ Time Step Interval $\times V_{a_{i}}$

Equation 5

When the summation of individual distances becomes equal to the total distance between the loading port and the offshore wind farm, it is assumed that the vessel arrives at the offshore wind farm. Thus,

Total Distance $=\sum_{i}^{n}$ Distance $_{i}$

Equation 6

Since the length of the working shift is assumed as 12 hours, the remaining time in the shift after the 'Travel time' is deducted is the summation of 'Productive time' and 'Non-productive time'. The 'Non-productive time' is the period, which the climate conditions and the daylight hour limitation causes delays and therefore CTVs stay at the port. The 'Productive time', which the technicians can perform the actual repairs, is the remaining period after 'Travel time' and 'Non-productive time' values are deducted from the length of the working shift.

\subsubsection{Helicopter}

A helicopter is assumed to perform all the repairs that CTVs can perform for the 'Failure modes' where the specified 'Required number of technicians' is equal or less than the number of technicians on the helicopter. At 
this stage, it is important to highlight that the preferred transportation system for minor failures is the CTVs; therefore if all the failures are attended by the CTVs, the helicopter stays at the heliport. If the weather conditions, especially sea conditions become worse and therefore if CTVs cannot travel, the helicopter can transfer technicians. Similarly, if the number of simultaneous failures is more than the CTV fleet can access in a single shift, the helicopter is again utilised.

\subsubsection{OAV and Jack-up Vessel}

The operability analysis of OAVs and jack-up vessels are dependent on the generated wind speed and wave height values. If either generated wind speed or wave height is higher than the 'Maximum operational wind speed' limit or 'Maximum operational wave height' limit, these vessels are required to cease the maintenance operation. In addition for jack-up vessels, the minimum weather window should be longer than the time required for jacking-up. In this case, the minimum weather window is defined by the consecutive time steps in which wave height and wind speed values are lower than the limiting wave height and wind speed for jacking operation. If the minimum weather window is shorter than the jacking-up period, the vessel stays at the site until the conditions are met. When the minimum weather window is sufficient enough, the vessel jacks-up. Due to the fact that the major O\&M activities require heavy equipment lifting, wind speed at hub level is an extra limitation for the jack-up O\&M operations. As for the jacking operation, the minimum weather window should be longer than the time required to perform the repair or the replacement. If the weather window is shorter than the repair period, the vessel waits as jacked-up until the conditions are met.

\subsubsection{Failure analysis}

The wind turbine system failure process is implemented using the methodology developed by Billinton (1970). Each wind turbine is modelled as a series of subsystems, for which a probability of 'moving from an operating state to a failed or reduced operating state' is envisaged. The probability of shifting states is governed by the component reliability, which is the probability that the component performs satisfactorily for the specified time interval $t$. In this context, the hazard rates $h(t)$, which are determined from observed annual failure rates in operational history and expert judgement, are utilised to calculate the reliability of the turbine components. Time dependent hazard rates provide flexibility to investigate the change of reliability throughout the simulated life time. If constant hazard rates are employed, there will no change in the reliability within the simulation period. In the simulation block, a uniformly distributed random number, $R$, in the interval 0 to 1 is generated at 
each time step and then employed to determine if a failure has occurred. In this context, if the generated random number is higher than the reliability value of the component at that particular time step, the component fails, otherwise continues functioning. If a component has a higher hazard rate, there is a higher probability that this particular components fails. The turbines are modelled as a series of sub-systems; therefore, any component failure causes entire turbine system failure. After a failure is identified, O\&M technicians are allocated to perform the repair. The transfer system of the O\&M technicians are defined by the 'Transportation type'. The allocation of the O\&M technicians and the actual O\&M activity is explained in the operational simulations section in detail.

\subsubsection{Operational simulations}

The operational simulation stage is the major section where all the information from previous blocks are synthesised. After identifying a failure, the simulations continue depending on the 'Transportation type' defined for that particular 'Failure mode'. When a maintenance team is allocated to a wind turbine, the priority is finalising the corrective maintenance task as soon as possible. If all the O\&M technicians are either occupied with repair operations or are not on duty, the turbine remains down, and an O\&M technician will not be assigned until the regular number of technicians becomes available to work. When O\&M technicians become available and are assigned to conduct the repair work, they can only be deployed to the failed turbine if the current weather conditions are within the turbine access limits as defined in the model inputs. If these conditions are not met, the O\&M technicians stay at the base/port and are only dispatched to the assigned turbine once the weather conditions improve within the access limits.

If the 'Transportation type' is a CTV/Helicopter;

These transportation systems are assumed to be occupied by the maximum number of technicians defined by the number of technicians for each transportation type at the beginning of each shift. When the failure is repaired, same technician team continues to do preventive maintenance (if required/applicable), otherwise stays in the wind turbine. The teams are not allocated to different wind turbines in a single shift. CTVs are allocated 
important consideration in the CTV allocation. If there are more than one CTV that can complete the task in a single shift, it is targeted to use minimum number of vessels; therefore it is prioritised to utilise a CTV which is already in the offshore wind farm. However, at the beginning of a repair shift, none of the CTVs would be allocated; therefore the number of CTVs in the wind farm would be zero. In this case, having the maximum number of working hours will be the consideration; thus, the number of turbines, which can potentially be visited by this particular CTV, can be maximised. When all the explained priorities are taken into account, the CTV with maximum number of working hours will be allocated at the beginning of the shift, and because this CTV will be in the wind farm, it will again be allocated for the subsequent repairs until that particular CTV runs out technicians or the number of visits becomes equal to the 'Maximum visit per CTV' value.

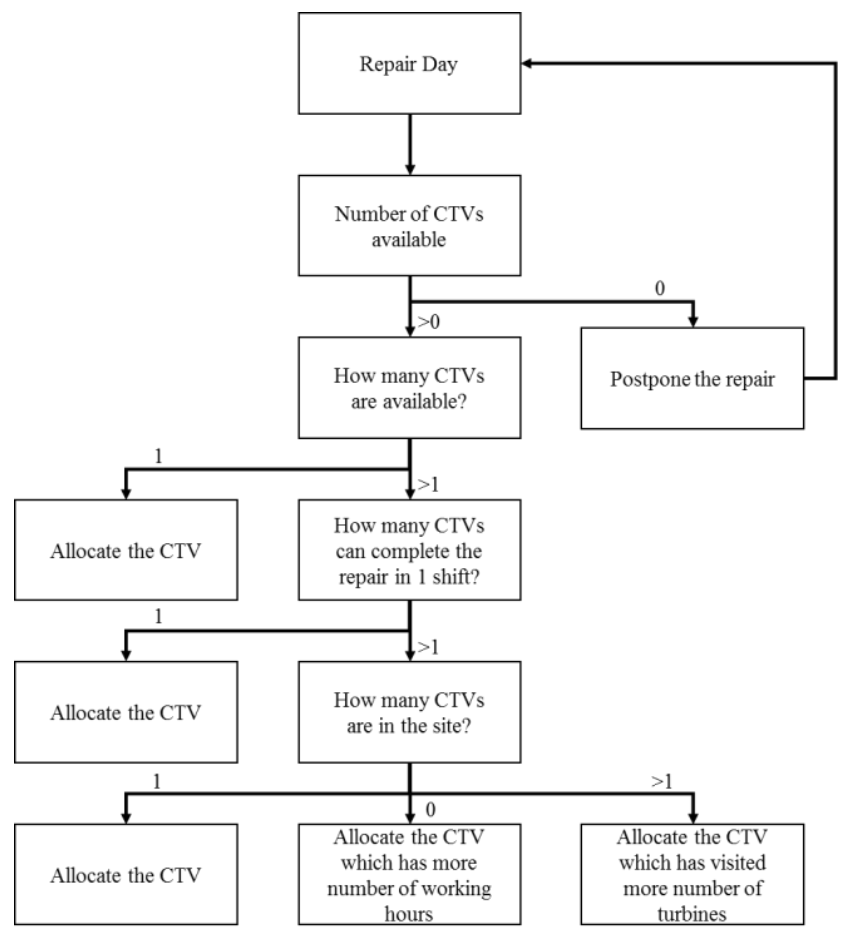

Figure 2: CTV allocation

Helicopter operations are simulated after the main CTV operations, however the repair process is simulated concurrently to other repair operations. Helicopter is only utilised if a number of criteria are met in order to represent the current operational practices. In a single shift, the helicopter can perform visits only to the turbines that have not been visited by any CTV (either due to high number simultaneous failures or higher accessibility criteria for the helicopter). In this case, the helicopter is utilised for the repairs subject to having remaining flight hours in the year and the site being accessible. 
$\mathrm{OAV}$ repairs are performed sequentially as soon as a failure of this category occurs. After the first failure is simulated, an OAV is mobilised. Once the mobilisation time is completed, the repairs can be performed subject to the 'Maximum operational wind speed' and 'Maximum operational wave height' limits of the OAV. The OAV remains in the wind farm for the duration of the charter period, but repair work and/or travels between wind turbines are only carried out during daylight hours and when climate conditions allow. Any unfinished maintenance at the end of charter period remains incomplete until another vessel is mobilised.

If the 'Transportation type' is a jack-up vessel;

Jack-up vessel repairs are performed sequentially as soon as a failure of this category occurs. After the first failure is simulated, a jack-up vessel is mobilised. Once the mobilisation time is complete repairs can be performed subject to the 'Maximum operational wind speed' and 'Maximum operational wave height' limits of the jack-up vessel. The jacking-up/down operations are determined by wave height and wind speed at sea level values, whilst the main repair operation is performed subject to wind speed at hub level criteria. The jack-up vessel remains available for the duration of the charter period and repair work and/or travels between wind turbines or to port to re-supply are only carried out when climate conditions allow. Any unfinished jobs at the end of charter period remain incomplete until another vessel is mobilised.

\subsection{Outputs}

The generic principle of the outputs sections is to calculate each output specifically for each simulation and then averaging these outputs when all the simulations are completed. Since, multiple simulations are run in order to cover all possible situations such as bad weather and good weather years, high number and low number of failures, etc., the outputs associated with each scenario will vary. By running a sufficiently large number of simulations, the average results will converge to a final value and the variability across simulations will provide a measure of uncertainty. The methodology provides major outputs such as availability, power production, vessel utilisation, mean time to repair values, and cost attributes in order to support the decision making process. This is required because, making the decision only by considering one attribute (i.e. costs) may lead the offshore wind farm developers to wrong directions. In this context, the developed methodology provides outputs under 5 different main output sections as listed below; 
- Wind farm availability and downtime outputs: Power based availability, turbine based availability, and percentage of completed preventive maintenance

- Power production specific outputs: Power produced and power lost

- Vessel specific outputs: Travel hours, utilisation, accessibility, contribution to downtime

- Failure specific outputs: Mean time to repair (MTTR) values

- OPEX cost specific outputs: Total charter cost, total fuel cost, total staff cost, total mobilisation cost, total OEM cost, total fixed cost, total O\&M cost and revenue loss.

Table 9: Variable inputs

\begin{tabular}{lll}
\hline Input name & Range & Interval \\
\hline Shift start & $06: 00$ am - 09:00 am & 1 hour \\
OAV charter length & 1 week - 4 weeks & 1 week \\
Jack-up vessel charter type & Fix on fail - Purchase & $N / A$ \\
Jack-up vessel charter length & 2 weeks - 8 weeks (Fix on fail) & 2 weeks \\
& 5 years (Purchase) & $N / A$ \\
Helicopter contract hour & 500 hours - 1000 hours (Helicopter is considered) & 250 hours \\
& 0 hours (Helicopter is not considered) & $N / A$ \\
Preventive maintenance start month & January - April - July - October & $N / A$ \\
O\&M technician allocation order & $\bullet$ Corrective maintenance or preventive maintenance & \\
& $\bullet$ Preventive maintenance after corrective maintenance & \\
\hline
\end{tabular}

\section{Case study}

To illustrate the developed model, a case study has been performed and presented next. The O\&M planning strategy is investigated for an offshore wind farm consisting of $1503.6 \mathrm{MW}$ turbines. The FINO 1 research mast, located $45 \mathrm{~km}$ off the coast of Germany is utilised for the analysis (FINO, 2014). The FINO 1 met mast is located within the German offshore wind development zone and can therefore be considered representative of current and future offshore wind farms in Europe. For this study the period 2004 - 2012 inclusive has been used. In order to cover different variations in the results due to randomisation of the climate parameters and the variables in the Monte-Carlo simulation process, 100 simulations with a period of 5 years are used. In this section, these inputs are defined to demonstrate a real case (Table A-1-Table A-7 in Appendix). Key inputs are varied as in Table 9 in order to investigate the O\&M strategy.

OAV charter length 
In this section, the results of the O\&M simulations are presented. Due to the fact there is no comprehensive information in the literature regarding the consequences of partially completed preventive maintenance, the completion of preventive maintenance is the first priority in the decision stage. Among 3840 scenarios that are generated through the variable inputs in Table 9, preventive maintenance is $100 \%$ completed in 1283 scenarios. In these 1283 scenarios, the 'Preventive maintenance start month' alternatives 'January', 'April', 'July', and 'October' months are observed 641,640,1, and 1 times, respectively. Therefore, it can be identified that starting preventive maintenance in the second half of the year does not provide operators with sufficient time to complete these activities. With respect to 'O\&M technician allocation order', 'Corrective maintenance or preventive maintenance', 'Preventive maintenance after corrective maintenance', 'Preventive maintenance only after corrective maintenance' alternatives are observed 640,641, and 2 times, respectively. These outputs show that it is unlikely to complete preventive maintenance if separate O\&M technicians are not allocated. The 'Shift start' values ‘6:00 am', ‘7:00 am', ‘8:00 am', '9:00 am' are observed 321, 320, 320, and 322 times, respectively. Thus, the 'Shift start' value (within 6:00 am and 9:00 am) does not affect the proportion of completed preventive maintenance. The 'Helicopter Contract hour' values '0', '500', ‘750', '1000' are observed $320,323,320$, and 320 times, respectively. In this respect, considering a helicopter within O\&M fleet does not bring a noticeable advantage in the completion of preventive maintenance activities. Similarly, 'OAV Charter length', 'Jack-up vessel Charter type', 'Jack-up vessel Charter length' are distributed equally, since these variables are not associated with preventive maintenance activities.

Figure 3 shows the total travel hours and the utilisation levels associated with each CTV. In this context, CTV1 is the most utilised CTV within simulation period, and therefore the travels performed by CTV-1 are over 3,000 hours within 5 years. Due to the fact that the methodology is developed to utilise a CTV as high as possible, the utilisation and travel values of other CTVs are relatively lower than CTV-1. This situation allows minimising the travel and fuel costs, because allocating multiple CTVs to multiple failures instead of allocating a single CTV to multiple failures, considering the priority to complete the repairs in a single shift, results in an increase in travel costs. This is also because, the travel time between the offshore wind farm and the O\&M port 

O\&M port and the offshore wind farm.
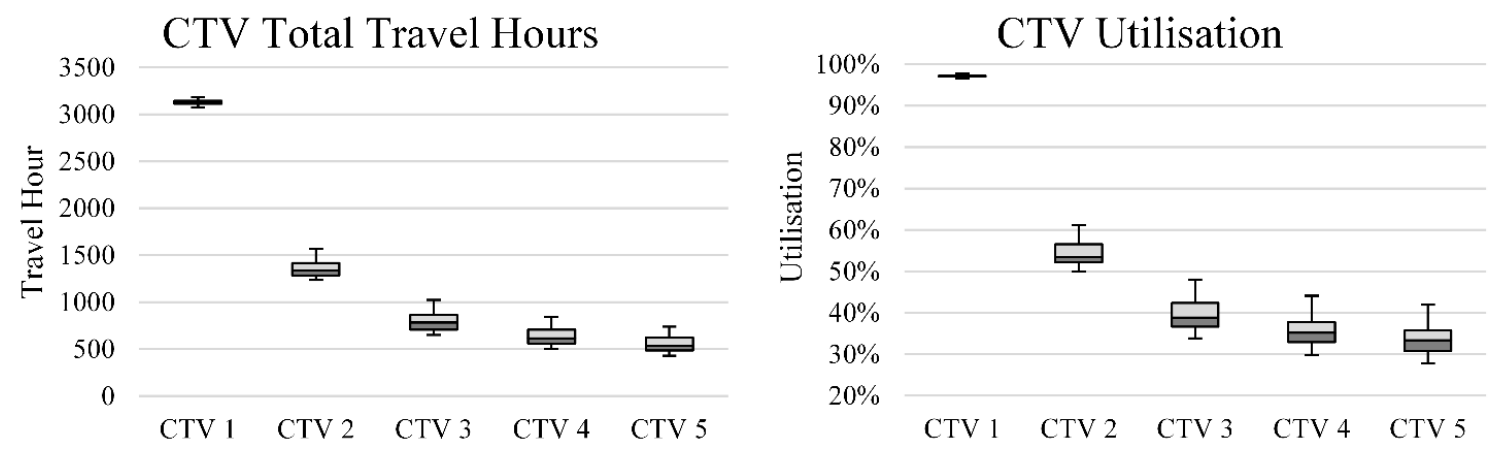

Figure 3: CTV travel hours and utilisation

The turbine downtime is required to be investigated in details to show the key aspects that cause the downtime. In this context, Figure 4 demonstrates the proportion of different reasons that contribute to the total turbine downtime. Since different transportation systems are allocated each 'Failure mode', the contribution to these figures are also demonstrated by the associated 'Transportation type'. The 'Manual reset' and 'Minor' failures are required to be repaired by the O\&M technicians allocated by either CTVs or helicopter. In this respect, 'Shift' and 'Weather' have the highest 2 proportions in the total 'Manual resets' and 'Minor' failure downtime by $48 \%$ and $38 \%$ (on average), respectively. Due to the fact that these transportation systems (CTV and helicopter) are utilised only in day shift, the failures during night can only be attended in the first following day shift. In addition, these transportation systems have relatively lower operability and accessibility limitations than other transportation types; therefore, the O\&M activities cannot be performed due to rough 'Weather' by $38 \%$. The remaining $14 \%$ of the failure downtime is shared by the 'Travel', 'Repairs', 'Resource'. It is important to highlight the fact that 'Repairs' account for only 3\% of the total 'Manual reset' and 'Minor' failure downtime, so actual O\&M activity has a very minor contribution to the total turbine downtime. 

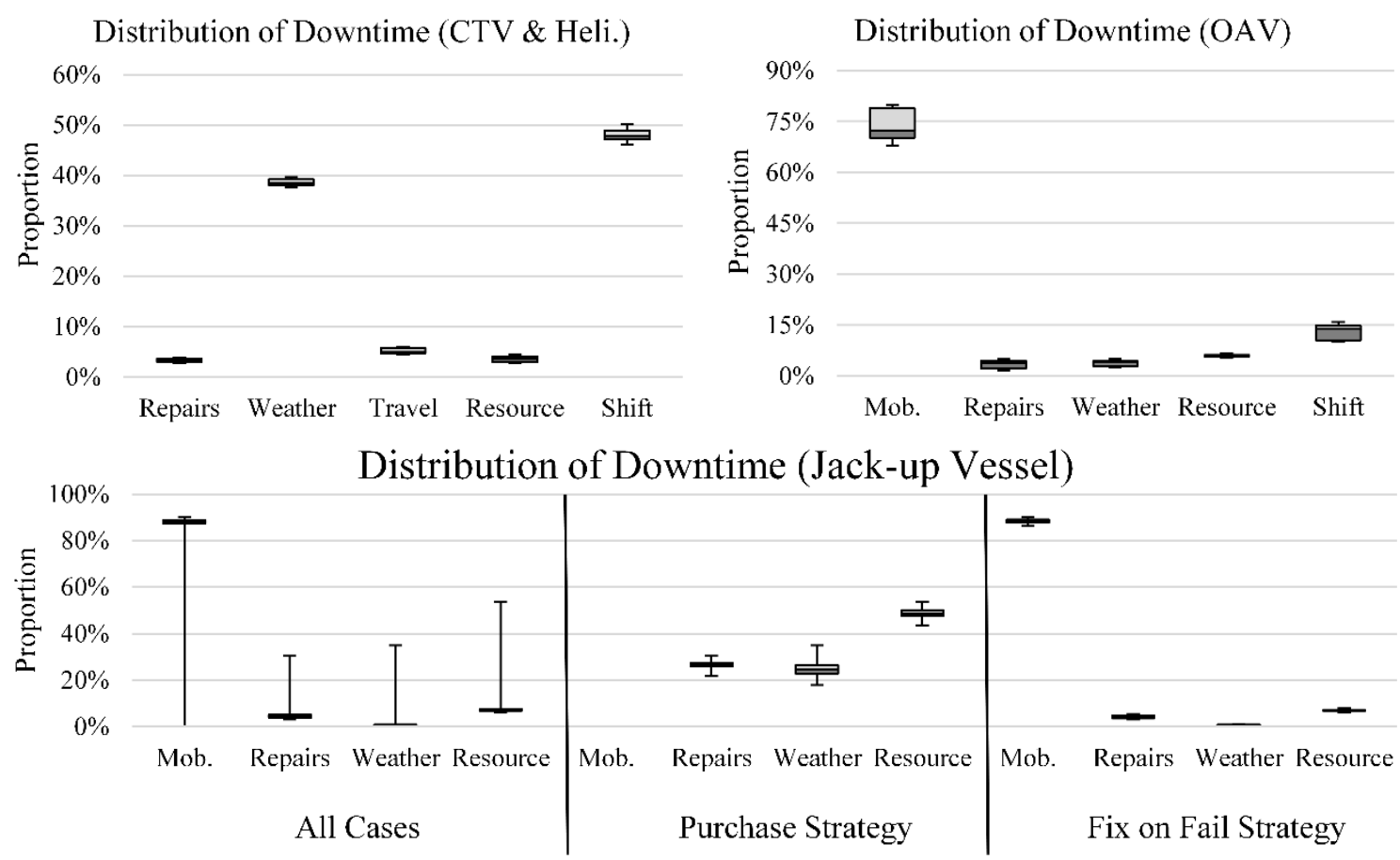

Figure 4: Distribution of downtime

The 'Medium' type O\&M activities are postponed 73\% (on average) due to OAV 'Mobilisation' (Figure 4). OAVs cannot perform repairs during the night shift, so 'Shift' has the second highest proportion in the total 'Medium' failure downtime by $13 \%$. OAV has better capability, so 'Weather' is not a major issue for the OAV. Due to the fact that the hazard rate of the 'Medium' failures is relatively lower, the number of simultaneous failures is also lower; therefore it is unlikely to postpone repairs due to lack of 'Resource'. Similar to 'Manual reset' and 'Minor' failures, 'Repairs' have a very minor contribution to the total downtime of the 'Medium' failures.

In order to ascertain higher accuracy in the results, downtime regarding jack-up vessel has to be investigated in detail. In this respect, the downtime is grouped under 'Purchase' and 'Fix on fail' strategies. Due to the fact that 'Mobilisation' is ' 0 ' for the 'Purchase' option, 'Repairs', 'Weather', and 'Resource' comprise all the downtime. With regard to 'Purchase' strategy, 'Repairs', 'Weather', 'Resource' account for 27\%, 24\%, 49\% (on average) of the total 'Major' failure downtime, respectively. With regard to 'Fix on fail' strategy, the 'Mobilisation' is the main cause of the downtime by $88 \%$ on average.

Figure 5 shows the distribution of total costs associated with each 'Transportation type'. Charter cost, fuel cost and technician cost account for $54 \%, 2 \%$ and $44 \%$ of the total CTV associated costs, respectively. With respect 
to helicopter, charter cost has the largest contribution by $77 \%$, while fuel cost and technician cost contribute by $13 \%$ and $10 \%$. In the OAV related operations, mobilisation cost, charter cost, fuel cost and technician cost account for $40 \%, 51 \%, 2 \%$ and $7 \%$ of the total OAV costs, respectively. On average, the charter cost of the jack-up vessel dominates the jack-up vessel associated costs by $84 \%$, while mobilisation cost, fuel cost and technician cost contribute by $13 \%, 1 \%, 2 \%$, respectively. However, the jack-up vessel charter cost and the mobilisation cost have significant uncertainty; therefore, these aspects are demonstrated in detail, categorised under 'Purchase' and 'Fix on fail' strategies. For 'Purchase' strategy, the cost of vessel is significantly higher; on the other hand, the mobilisation cost is ' 0 '. When the 'Charter length' values for the 'Fix on fail' strategy are increased, the total charter costs increase proportionally to the number of days that the vessel is chartered. On the other hand, the mobilisation costs decreases, because when the jack-up vessel is chartered for longer period, the number of failures that can be repaired in a single charter period increases; thus the number of charters, and eventually the number of mobilisation operations decrease.

\section{Total Transportation Costs}

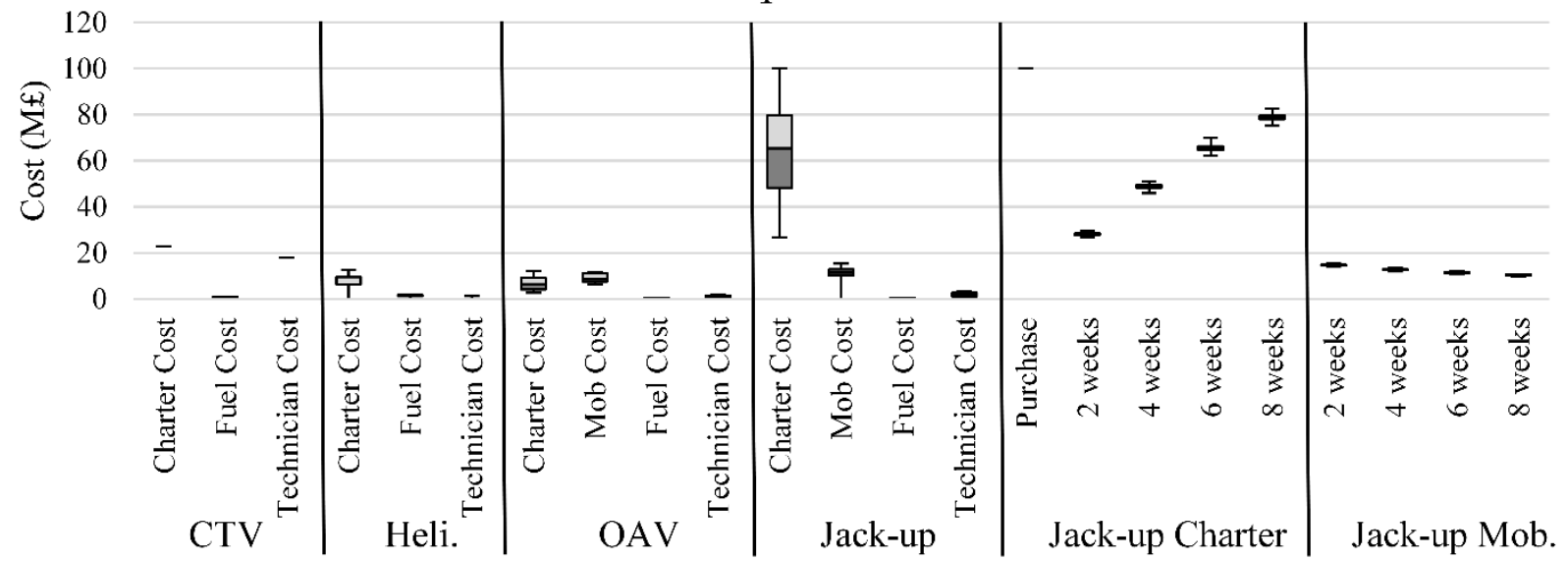

Figure 5: Distribution of transportation system associated costs

Figure 6 demonstrates the distribution of total O\&M costs. The graph on the left hand side shows the total O\&M cost per unit power production (£/MWh), whilst the graph on the right hand side shows the total O\&M cost spent within 5 years (simulation period). Cost per unit power production is a well-known criterion to assess the performance of the O\&M activities; on the other hand, it is also important to identify the actual costs that operators have to finance. In this context, the total direct O\&M cost consist of staff costs, OEM costs, fixed costs, and transport costs. The total O\&M costs are calculated by considering the lost revenue and the total 
direct O\&M costs. It can be seen that the staff, the OEM, and the fixed costs show significantly low uncertainty, on the other hand the transport costs and the lost revenue have higher uncertainty. On average, the staff, OEM, fixed, transport costs and lost revenue account for $7 \%, 9 \%, 13 \%, 38 \%$, and $33 \%$ of the total O\&M costs, respectively.
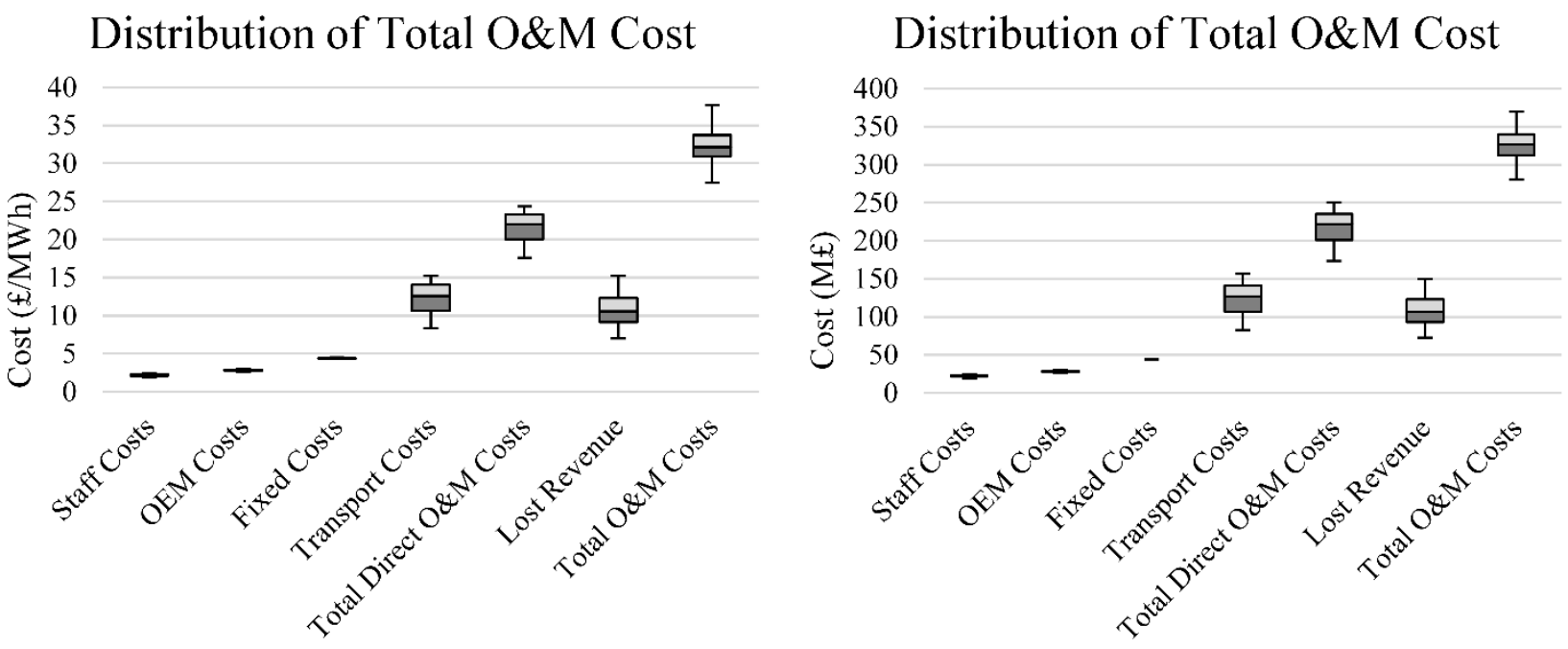

6 Figure 6: Distribution of total O\&M cost

Considering all the information above, the best and the worst O\&M planning configurations are listed in Table 11 and Table 12, respectively. The variables in Table 11 and Table 12 are represented by the designated values as in Table 10 for presentation purposes. In these tables the rankings of the configurations are identified from the total O\&M cost/production, since this output considers total O\&M cost and total power production, and therefore shows the cost effectiveness of the O\&M strategy.

As shown in Table 11 and Table 12, the best configurations include helicopter with '750' and '1000' contract hours; on the contrary, helicopter is not considered in the worst configurations, which shows the importance of the helicopter within the O\&M fleet. The daily charter rate of the OAV is relatively higher; on the other hand the production loss and the revenue loss due to OAV unavailability are more significant. Therefore, the OAV is chartered ' 21 ' days or longer in the best configurations. The 'Fix on Fail' strategy is identified as the most and the worst cost-effective jack-up vessel chartering strategy, but the charter length varies in the configurations. The best jack-up vessel charter length is '14' days; because, the failures associated with the jack-up vessel occur less frequently, so chartering the jack-up vessel for a longer period increases the revenue loss significantly, which is not compensated by the power production increase. From availability point of view, $3 \%$ improvement 
can be expected. Moreover, the total O\&M cost can be decreased by $24 \%$ (from $36.64 £ / \mathrm{MWh}$ to $27.71 £ / \mathrm{MWh}$ ) by selecting the most favourable plan for the O\&M fleet and associated activities. Therefore, the financial and operational aspects are improved through the implementation of the methodology.

Table 10: Designated values for the variables

\begin{tabular}{|c|c|c|}
\hline Value & Variable name & Unit \\
\hline 1 & Shift start & hour \\
\hline 2 & OAV charter length & days \\
\hline 3 & Jack-up vessel charter type & $N / A$ \\
\hline A & - Fix on fail & \\
\hline B & - Purchase & \\
\hline 4 & Jack-up vessel charter length & days \\
\hline 5 & Helicopter contract hour & hours \\
\hline 6 & Preventive maintenance start month & $N / A$ \\
\hline 7 & O\&M technician allocation order & $N / A$ \\
\hline A & - Corrective maintenance or preventive maintenance & $N / A$ \\
\hline B & - Preventive maintenance after corrective maintenance & $N / A$ \\
\hline $\mathrm{C}$ & - Preventive maintenance only after corrective maintenance & $N / A$ \\
\hline 8 & Power based availability & $\%$ \\
\hline 9 & Total O\&M cost & $£ / M W h$ \\
\hline
\end{tabular}

Table 11: Best 10 offshore wind farm O\&M planning configurations

\begin{tabular}{|c|c|c|c|c|c|c|c|c|}
\hline \multicolumn{9}{|c|}{ Variable (referring to Table 10) } \\
\hline 1 & 2 & 3 & 4 & 5 & 6 & 7 & 8 & 9 \\
\hline 8 & 28 & $\mathrm{~A}$ & 14 & 750 & January & $\mathrm{A}$ & 0.9391 & 27.46 \\
\hline 7 & 28 & A & 14 & 750 & January & $\mathrm{B}$ & 0.9389 & 27.47 \\
\hline 9 & 21 & A & 14 & 1000 & April & A & 0.9409 & 27.53 \\
\hline 8 & 28 & A & 14 & 750 & January & $\mathrm{B}$ & 0.9383 & 27.54 \\
\hline 7 & 21 & A & 14 & 1000 & April & $\mathrm{B}$ & 0.9399 & 27.56 \\
\hline 7 & 28 & A & 14 & 1000 & April & A & 0.9399 & 27.59 \\
\hline 8 & 28 & A & 14 & 1000 & January & B & 0.9404 & 27.60 \\
\hline 7 & 21 & A & 14 & 1000 & January & B & 0.9393 & 27.67 \\
\hline 6 & 28 & A & 14 & 750 & January & A & 0.9377 & 27.68 \\
\hline 9 & 21 & A & 14 & 1000 & April & B & 0.9392 & 27.71 \\
\hline
\end{tabular}

Table 12: Worst 10 offshore wind farm O\&M planning configurations

\begin{tabular}{lllllllll}
\hline & \multicolumn{7}{c}{ Variable (referring to Table 10) } & \\
1 & 2 & 3 & 4 & 5 & 6 & 7 & 8 & 9 \\
\hline 7 & 7 & A & 56 & 0 & April & B & 0.9032 & 37.62 \\
9 & 7 & A & 56 & 0 & April & A & 0.9079 & 37.23 \\
6 & 7 & A & 56 & 0 & April & A & 0.9070 & 37.07 \\
6 & 7 & A & 56 & 0 & January & B & 0.9069 & 36.97 \\
9 & 7 & A & 56 & 0 & April & B & 0.9078 & 36.89 \\
6 & 7 & A & 56 & 0 & April & B & 0.9077 & 36.85 \\
9 & 7 & A & 56 & 0 & January & B & 0.9079 & 36.83 \\
6 & 7 & A & 56 & 0 & January & A & 0.9078 & 36.78 \\
7 & 7 & A & 56 & 0 & April & A & 0.9065 & 36.71 \\
8 & 7 & A & 56 & 0 & January & B & 0.9072 & 36.64 \\
\hline
\end{tabular}


In this study, a comprehensive novel methodology of O\&M planning for offshore wind farms is introduced towards optimum O\&M cost, minimum revenue loss, and maximum power production. Climate parameters, failure characteristics of different failure modes, and different transportation systems (helicopter, crew transfer vessel, offshore access vessel and jack-up vessel) are simulated within the operational phase of an offshore wind farm. The results are demonstrated to support the decision making related to the O\&M and logistics strategy. The consequences of different decisions can be assessed and favourable solutions, which bring the highest financial and operational benefits, can be selected.

In this context, it is identified that the cost of jack-up vessel related operations is significantly higher than any other transportation system in the O\&M fleet. Therefore, the jack-up vessel charter period has to be investigated carefully, before chartering the jack-up vessel. From preventive maintenance point of view, second half of the year can be too late to start these operations. Due to higher accessibility than conventional CTVs, helicopter is an important aspect in the O\&M fleet; however, the helicopter operations can be performed in a more costeffective way when the offshore wind sector becomes more mature. It is clear that human interventions at offshore environment need to be reduced and the possibility for remote condition monitoring need to be fully exploited. As the number of turbines in offshore wind projects increases, and the wind farms are located further away from shore, there is a need to develop specialised new O\&M vessels and transfer systems that will provide access to turbines throughout the year in rough sea conditions. New approaches may involve moving from portbased operations to ship-based strategies.

\section{Acknowledgements}

The authors would like to express their appreciation to Scottish Power Renewables (SPR), Scottish and Southern Energy (SSE), and Technip for their valuable and constructive suggestions during the planning and development of this research work. For climate data from the FINO project, the authors thank the BMU (Bundesministerium fuer Umwelt, Federal Ministry for the Environment, Nature Conservation and Nuclear Safety) and the PTJ ARCHIE-WeSt High Performance Computer (www.archie-west.ac.uk). EPSRC grant no. EP/K000586/1. This work is funded by the Technology Innovation Centre (TIC), University of Strathclyde. 


\section{References}

Housing needs of the Kurdish community in London : research report. Kurdish Housing Association, London.

Al-Salem, K., Al-Nassar, W., Tayfun, A., 2006. Risk analysis for capsizing of small vessels. Ocean engineering 33 (5-6), 788-797.

Anderson, C., Horne, J.A., 2006. Sleepiness enhances distraction during a monotonous task. Sleep 29 (4), $573-$ 576.

Belenky, G., Wesensten, N.J., Thorne, D.R., Thomas, M.L., Sing, H.C., Redmond, D.P., Russo, M.B., Balkin, T.J., 2003. Patterns of performance degradation and restoration during sleep restriction and subsequent recovery: a sleep dose-response study. Journal of Sleep Research 12 (1), 1-12.

Besnard, F., Patrikssont, M., Strombergt, A.B., Wojciechowski, A., Bertling, L., 2009. An optimization framework for opportunistic maintenance of offshore wind power system, PowerTech, 2009 IEEE Bucharest, Romania, pp. 1-7.

Billinton, R., 1970. Power system reliability evaluation. Gordon and Breach, New York, USA.

Bossanyi, E.A., Strowbridge, A.G., 1992. Assessing windfarm operation and maintenance requirements, British Wind Energy Association Conference, Nottingham, UK.

Bussel, G.J.W.V., Bierbooms, W.A.A.M., 2003. The DOWEC Offshore Reference Windfarm: analysis of transportation for operation and maintenance. Wind Engineering 27 (5).

Bussel, G.J.W.V., Schöntag, C., 1997. Operation and Maintenance Aspects of Large Offshore Windfarms, European Wind Energy Conference Dublin, Ireland.

Cunha, C., Guedes Soares, C., 1999. On the choice of data transformation for modelling time series of significant wave height. Ocean engineering 26 (6), 489-506.

Curvers, A.P.W.M., Rademakers, L.W.M.M., 2004a. Optimisation of the O\&M costs to lower the energy costs (RECOFF), Denmark.

Curvers, A.P.W.M., Rademakers, L.W.M.M., 2004b. WP6 Operation and Maintenance Task 1: Standardisation of collecting failures and maintenance data, Denmark.

Dai, L., Ehlers, S., Rausand, M., Utne, I.B., 2013. Risk of collision between service vessels and offshore wind turbines. Reliability Engineering \& System Safety 109 (0), 18-31.

Dalgic, Y., Lazakis, I., Dinwoodie, I., McMillan, D., Revie, M., 2015a. Cost benefit analysis of mothership concept and investigation of optimum operational practice for offshore wind farms, 12th Deep Sea Offshore Wind R\&D Conference, Trondheim, Norway.

Dalgic, Y., Lazakis, I., Dinwoodie, I., McMillan, D., Revie, M., 2015b. The influence of multiple working shifts for offshore wind farm O\&M activities - StrathOW-OM Tool, The Royal Institution of Naval Architects, Design \& Operation of Offshore Wind Farm Support Vessels, London, UK.

Dalgic, Y., Lazakis, I., Turan, O., 2014. Vessel charter rate estimation for offshore wind O\&M activities. Developments in Maritime Transportation and Exploitation of Sea Resources, Vol 2, 899-907.

Dalgic, Y., Lazakis, I., Turan, O., 2015c. Investigation of Optimum Crew Transfer Vessel Fleet for Offshore Wind Farm Maintenance Operations. Wind Engineering 39 (1), 31-52. 
Dalgic, Y., Lazakis, I., Turan, O., Judah, S., 2015d. Investigation of optimum jack-up vessel chartering strategy for offshore wind farm O\&M activities. Ocean engineering 95 (0), 106-115.

Dinwoodie, I., McMillan, D., Revie, M., Lazakis, I., Dalgic, Y., 2013. Development of a Combined Operational and Strategic Decision Support Model for Offshore Wind. Energy Procedia 35 (0), 157-166.

DNV, 2011. Design of Offshore Wind Turbine Structures. DNV, Norway, pp. 1-213.

EWEA, 2011. Wind in our Sails - The coming of Europe's offshore wind energy industry, in: Azau, S., Casey, Z. (Eds.), Brussels, pp. 1-93.

Fingersh, L., Hand, M., Laxson, A., 2006. Wind Turbine Design Cost and Scaling Model. National Renewable Energy Laboratory.

FINO, 2014. FINO 1,2,3 - Forschungsplattformen in Nord-und Ostsee Nr. 1,2,3, Germany.

Fırtın, E., Güler, Ö., Akdağ, S.A., 2011. Investigation of wind shear coefficients and their effect on electrical energy generation. Applied Energy 88 (11), 4097-4105.

Hill, D.C., McMillan, D., Bell, K.R.W., Infield, D., 2012. Application of Auto-Regressive Models to U.K. Wind Speed Data for Power System Impact Studies. Sustainable Energy, IEEE Transactions on 3 (1), 134-141.

Joint Aviation Authorities, 2004. Joint Aviation Requirements JAR-OPS 3: Commercial Air Transportation (Helicopters), Netherlands.

Junginger, M., Faaij, A., Turkenburg, W.C., 2004. Cost reduction prospects for the offshore wind energy sector. Wind Engineering 28 (1), 97-118.

Justus, C.G., Mikhail, A., 1976. Height variation of wind speed and wind distributions statistics. Geophysical Research Letters 3 (5), 261-264.

Kaldellis, J.K., Kapsali, M., 2013. Shifting towards offshore wind energy-Recent activity and future development. Energy Policy 53, 136-148.

Krohn, S., Morthorst, P.-E., Awerbuch, S., 2009. The Economics of Wind Energy. EWEA, Brussels, Belgium.

Lyrner, T., Pahlke, T., Ley, C., Giebel, G., Gram-Hansen, K., Ahlf, A., Myszkowski, M., Giebhardt, J., 2006. Advanced Maintenance and Repair for Offshore Wind Farms using Fault Prediction and Condition Monitoring Techniques (OffShoreM\&R), Brussels, Belgium.

Manwell, J.F., McGowan, J.G., Rogers, A.L., 2009. Wind energy explained : theory, design and application. John Wiley, Chichester, UK.

Neumaier, A., Schneider, T., 2001. Estimation of parameters and eigenmodes of multivariate autoregressive models. Acm Transactions on Mathematical Software 27 (1), 27-57.

O'Connor, M., Lewis, T., Dalton, G., 2013. Weather window analysis of Irish west coast wave data with relevance to operations \&amp; maintenance of marine renewables. Renewable Energy 52 (0), 57-66.

Parkes, K.R., 2010. Offshore working time in relation to performance, health and safety. University of Oxford, Oxford, UK.

Philips, J.L., Morgan, C.A., Jacquimin, J., 2006. Evaluating O\&M Strategies for offshore wind farms through simulation - the impact of wave climatology, OWEMES, Civitavecchia, Italy. 
Rademakers, L.W.M.M., Braam, H., Obdam, T.S., 2011. 18 - Operation and maintenance of offshore wind energy systems, in: Sørensen, J.D., Sørensen, J.N. (Eds.), Wind Energy Systems. Woodhead Publishing, pp. 546-583.

Ramakers, R., Verbruggen, T., Rademakers, L.W.M.M., 2004. Work Package 6 Task 2 : Labour Safety (Health and Safety), Denmark.

Santos, F.P., Teixeira, A.P., Soares, C.G., 2013. Influence of logistic strategies on the availability and maintenance costs of an offshore wind turbine, Safety, Reliability and Risk Analysis. CRC Press, pp. 791-799.

Stopford, M., 2009. Maritime economics, 3rd ed. ed. Routledge, London.

Stratford, P., 2007. Assessing the Financial Viability of Offshore Wind Farms, European Wind Energy Conference (EWEC 2007), Milan, Italy.

Tavner, P., 2012. Offshore Wind Turbines: Reliability, availability and maintenance. The Institution of Engineering and Technology, London, UK.

The Crown Estate, 2012. Offshore Wind Cost Reduction Pathways Study, London, UK.

Townsend, N.C., Coe, T.E., Wilson, P.A., Shenoi, R.A., 2012. High speed marine craft motion mitigation using flexible hull design. Ocean engineering 42 (0), 126-134.

Van Bussel, G.J.W., Zaaijer, M.B., 2001. Reliability, availability and maintenance aspects of large-scale offshore wind farms, a concepts study, Proceedings of MAREC Marine Renewable Energies Conference, Newcastle, UK, pp. 119-126.

Walker, R.T., van Nieuwkoop-McCall, J., Johanning, L., Parkinson, R.J., 2013. Calculating weather windows: Application to transit, installation and the implications on deployment success. Ocean engineering 68 (0), 88101.

Watson, D.G.M., 1998. Chapter 19 Operational economics, in: Watson, D.G.M. (Ed.), Elsevier Ocean Engineering Series. Elsevier, pp. 491-510.

WindPower Offshore, 2012. Global Offshore, Special Report, London, UK.

WindPower Offshore, 2014. Wind Power Montly - Power Transfer - October, London, UK.

Wu, M., 2014. Numerical analysis of docking operation between service vessels and offshore wind turbines. Ocean engineering 91 (0), 379-388.

\section{Appendix}

Table A-1: Climate inputs

\begin{tabular}{|c|c|c|c|c|c|c|c|c|}
\hline No & Name & \multicolumn{6}{|l|}{ Value } & Unit \\
\hline 1 & Wind speed & \multicolumn{6}{|c|}{ FINO 1 database } & $\mathrm{m} / \mathrm{s}$ \\
\hline 2 & Wave height & \multicolumn{6}{|c|}{ FINO 1 database } & $m$ \\
\hline 3 & Wave period & \multicolumn{6}{|c|}{ FINO 1 database } & $\sec$ \\
\hline 4 & Sun-rise time & \multicolumn{6}{|c|}{ FINO 1 observatory [N 54º0' $\left.53,5^{\prime \prime}\right]$} & $h h: m m$ \\
\hline 5 & Sun-set time & \multicolumn{6}{|c|}{ FINO 1 observatory [E $\left.6^{\circ} 35^{\prime} 15,5^{\prime \prime}\right]$} & hh: $\mathrm{mm}$ \\
\hline \multirow[t]{5}{*}{6} & Probability of good visibility & January & February & March & April & May & June & \\
\hline & & 93 & 87 & 87 & & & & $\%$ \\
\hline & & July & August & September & October & November & December & \\
\hline & & 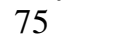 & 82 & 87 & 86 & 92 & 90 & $\%$ \\
\hline & Shear component & 0.1 & & & & & & $N / A$ \\
\hline
\end{tabular}

Table A-2: Transportation inputs (CTVs) 


\begin{tabular}{llll}
\hline No & Name & Value & Unit \\
\hline 1 & Number of CTVs & 5 & vessel \\
2 & Vessel type & Catamaran & N/A \\
3 & Length & 18 & $\mathrm{~m}$ \\
4 & Breadth & 6 & $\mathrm{~m}$ \\
5 & Draught & 1.8 & $\mathrm{~m}$ \\
6 & Displacement & 35 & ton \\
7 & Installed power & 1118 & $\mathrm{~kW}$ \\
8 & Technician capacity & 12 & person \\
9 & Operational speed & 24 & $\mathrm{knot}$ \\
10 & Fuel consumption & 0.24 & mt/hour \\
11 & Max. op. wave height & 1.5 & $\mathrm{~m}$ \\
12 & Max. op. wind speed & 25 & $\mathrm{~m} / \mathrm{s}$ \\
13 & Shift start & $06: 00-07: 00-08: 00-09: 00$ (referring to Table 9) \\
14 & Maximum visit per CTV & 4 & hh:mm \\
15 & Inter transit time & 10 & turbine \\
16 & Time to start work & 30 & minute \\
17 & Minimum working limit & 2 & minute \\
\hline
\end{tabular}

1 Table A-3: Transportation inputs (Helicopter)

\begin{tabular}{llll}
\hline No & Name & Value & Unit \\
\hline 1 & Contract hour & $0-500-750-1000$ (referring to Table 9) & hour \\
2 & Operational speed & 50 & knot \\
3 & Fuel consumption & 0.4 & $\mathrm{mt} / \mathrm{hour}$ \\
4 & Max. op. wave height & 4 & $\mathrm{~m}$ \\
5 & Max. op. wind speed & 18 & $\mathrm{~m} / \mathrm{s}$ \\
\hline
\end{tabular}

2 Table A-4: Transportation inputs (OAV)

\begin{tabular}{llll}
\hline No & Name & Value & Unit \\
\hline 1 & Charter length & $7-14-21-28$ (referring to Table 9) & day \\
2 & Mobilisation time & 21 & day \\
3 & Operational speed & 13.5 & $\mathrm{knot}$ \\
4 & Fuel consumption & 0.2 & $\mathrm{mt} / \mathrm{hour}$ \\
5 & Max. op. wave height & 2 & $\mathrm{~m}$ \\
6 & Max. op. wind speed & 25 & $\mathrm{~m} / \mathrm{s}$ \\
\hline
\end{tabular}

3 Table A-5: Transportation inputs (Jack-up vessel)

\begin{tabular}{llll}
\hline No & Name & Value & Unit \\
\hline 1 & Charter type & Fix on fail-Purchase (referring to Table 9) & N/A \\
2 & Charter length & $14-28-42-56$ (referring to Table 9) & day \\
3 & Mobilisation time (opt.) & 7 & day \\
4 & Mobilisation time (exp.) & 60 & day \\
5 & Mobilisation time (pes.) & 120 & day \\
6 & Batch repair threshold & 1 & failure \\
7 & Component capacity & 3 & component \\
8 & Port re-supply time & 24 & hour \\
9 & Jack-up time & 3 & hour \\
10 & Hub removal time & 8 & hour \\
1 & Operational speed & 11 & $\mathrm{knot}$ \\
12 & Fuel consumption & 0.55 & $\mathrm{mt} / \mathrm{hour}$ \\
13 & Max. op. wave height & 2.8 & $\mathrm{~m}$ \\
14 & Max. op. wind speed & 36.1 & $\mathrm{~m} / \mathrm{s}$ \\
15 & Lifting wind speed limit & 15.3 & $\mathrm{~m} / \mathrm{s}$ \\
\hline
\end{tabular}

4 Table A-6: Wind farm/turbine inputs

\begin{tabular}{llll}
\hline No & Name & Value & Unit \\
\hline 1 & Number of turbines & 150 & turbine \\
2 & Generation capacity & 3.6 & MW \\
3 & Distance & 20 & nmile
\end{tabular}




\begin{tabular}{|c|c|c|c|c|c|c|}
\hline No & Name & \multicolumn{4}{|l|}{ Value } & Unit \\
\hline 4 & Hub height & \multicolumn{4}{|l|}{77.5} & $m$ \\
\hline 5 & Power curve & \multicolumn{4}{|c|}{ 3.6 MW turbine power curve } & $N / A$ \\
\hline 6 & Cut in speed & \multicolumn{4}{|l|}{4} & $m / s$ \\
\hline 7 & Cut out speed & \multicolumn{4}{|l|}{25} & $\mathrm{~m} / \mathrm{s}$ \\
\hline 8 & Failure mode & Manual Reset & Minor & Medium & Major & $N / A$ \\
\hline 9 & Required repair time & 1 hour & 4 hours & 12 hours & 24 hours & hour \\
\hline 10 & Required number of technicians & 1 & 3 & 6 & 8 & person \\
\hline 11 & Transportation type & CTV/Helicopter & CTV/Helicopter & OAV & Jack-up vessel & $N / A$ \\
\hline 12 & Repair window & Cumulative & Cumulative & Cumulative & Single & hour \\
\hline 13 & Failure impact & $100 \%$ & $100 \%$ & $100 \%$ & $100 \%$ & $\%$ \\
\hline 14 & Failure distribution & 5/turbine/year & 2/turbine/year & $0.3 /$ turbine/year & $0.1 /$ turbine/year & $N / A$ \\
\hline 15 & Required preventive maintenance & \multicolumn{4}{|l|}{50} & hour \\
\hline 16 & Preventive maintenance technicians & \multicolumn{4}{|l|}{3} & person \\
\hline 17 & Preventive maintenance start month & \multicolumn{4}{|c|}{ January-April-July-October (referring to Table 9) } & $N / A$ \\
\hline 18 & O\&M technician & \multicolumn{4}{|c|}{ (referring to Table 9) } & $N / A$ \\
\hline & allocation order & \multicolumn{5}{|c|}{ Corrective maintenance or preventive maintenance } \\
\hline & & \multicolumn{5}{|c|}{ Preventive maintenance after corrective maintenance } \\
\hline & & \multicolumn{5}{|c|}{ Preventive maintenance only after corrective maintenance } \\
\hline
\end{tabular}

Table A-7: Cost inputs

\begin{tabular}{|c|c|c|c|c|c|c|}
\hline No & Name & \multicolumn{4}{|l|}{ Explanation } & Unit \\
\hline 1 & Electricity price & \multicolumn{4}{|l|}{150} & $£ / M W h$ \\
\hline 2 & CTV charter cost & \multicolumn{4}{|l|}{2,500} & $£ / \mathrm{CTV} /$ day \\
\hline 3 & CTV technician cost & \multicolumn{4}{|l|}{60,000} & $£ /$ tech/year \\
\hline 4 & CTV fixed cost & \multicolumn{4}{|l|}{50,000} & £/CTV/year \\
\hline 5 & Helicopter charter cost & \multicolumn{4}{|l|}{2,500} & E/hour \\
\hline 6 & Helicopter technician cost & \multicolumn{4}{|l|}{80,000} & $£ /$ tech/year \\
\hline 7 & OAV charter cost & \multicolumn{4}{|l|}{10,000} & $£ /$ day \\
\hline 8 & OAV mobilisation cost & \multicolumn{4}{|l|}{200,000} & $£ / \mathrm{mob}$ \\
\hline 9 & OAV technician cost & \multicolumn{4}{|l|}{100,000} & $£ /$ tech/year \\
\hline 10 & Jack-up vessel charter cost & \multicolumn{4}{|l|}{110,000} & $£ / d a y$ \\
\hline 11 & Jack-up vessel mobilisation cost & \multicolumn{4}{|l|}{800,000} & $£ / \mathrm{mob}$ \\
\hline 12 & Jack-up vessel technician cost & \multicolumn{4}{|l|}{100,000} & $£ /$ tech/year \\
\hline 13 & Jack-up vessel CAPEX & \multicolumn{4}{|l|}{$100,000,000$} & $£$ \\
\hline 14 & CTV fuel cost & \multicolumn{4}{|l|}{450} & $£ / m t$ \\
\hline 15 & Helicopter fuel cost & \multicolumn{4}{|l|}{1,200} & $£ / m t$ \\
\hline 16 & OAV fuel cost & \multicolumn{4}{|l|}{300} & $E / m t$ \\
\hline 17 & Jack-up vessel fuel cost & \multicolumn{4}{|l|}{300} & $E / m t$ \\
\hline 18 & Preventive maintenance cost & \multicolumn{4}{|l|}{5000} & $£ /$ turbine/year \\
\hline \multirow[t]{2}{*}{19} & Component repair cost & Manual Reset & Minor & Medium & Major & \\
\hline & & & 5000 & 25,000 & 200,000 & E/repair \\
\hline 20 & Port and operations cost & \multicolumn{4}{|l|}{800,000} & E/year \\
\hline 21 & Insurance cost & \multicolumn{4}{|l|}{$8,000,000$} & £/year \\
\hline
\end{tabular}

